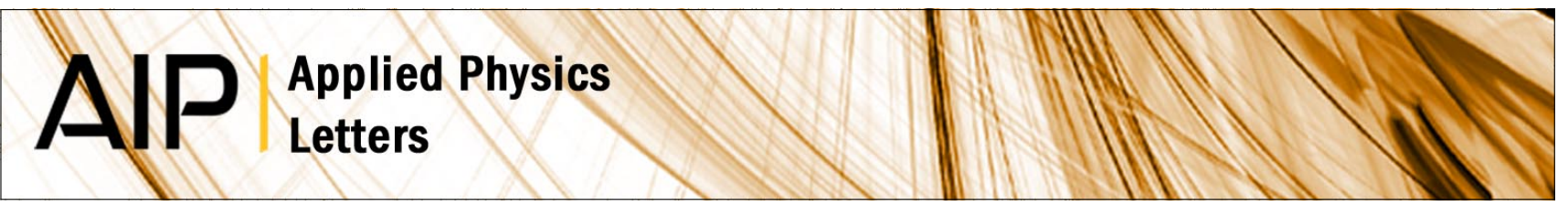

\title{
Growth and luminescence properties of micro- and nanoneedles in sintered $\mathrm{CdSe}$
}

A. Urbieta, P. Fernández, and J. Piqueras

Citation: Appl. Phys. Lett. 85, 5968 (2004); doi: 10.1063/1.1830083

View online: http://dx.doi.org/10.1063/1.1830083

View Table of Contents: http://apl.aip.org/resource/1/APPLAB/v85/i24

Published by the AIP Publishing LLC.

\section{Additional information on Appl. Phys. Lett.}

Journal Homepage: http://apl.aip.org/

Journal Information: http://apl.aip.org/about/about_the_journal

Top downloads: http://apl.aip.org/features/most_downloaded

Information for Authors: http://apl.aip.org/authors

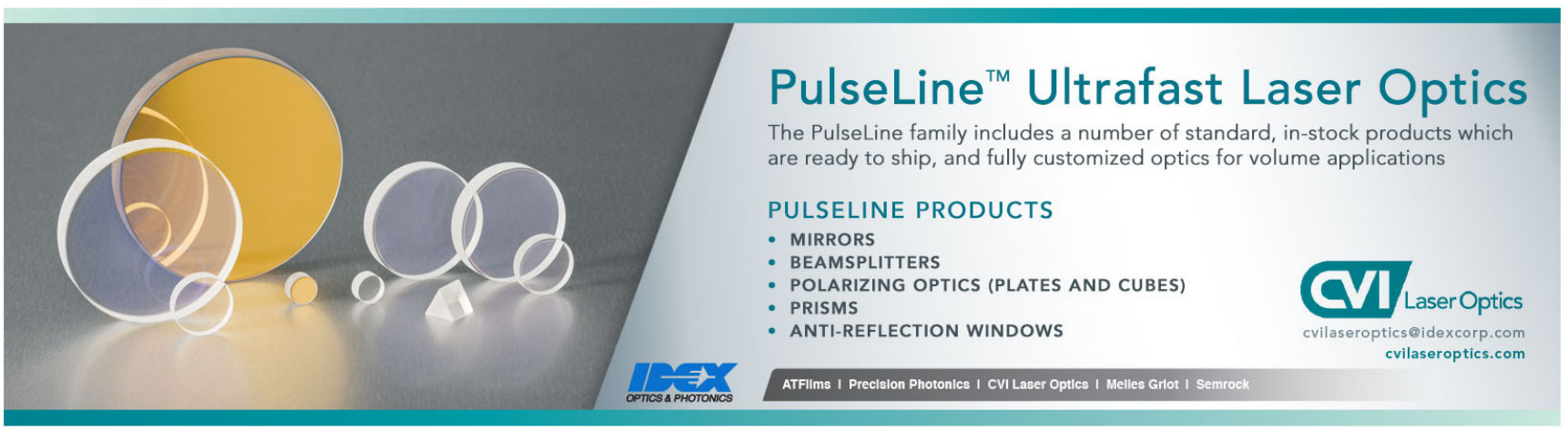




\title{
Growth and luminescence properties of micro- and nanoneedles in sintered CdSe
}

\author{
A. Urbieta, P. Fernández, and J. Piqueras ${ }^{a)}$ \\ Departamento de Física de Materiales, Facultad de Ciencias Físicas, \\ Universidad Complutense de Madrid, 28040 Madrid, Spain
}

(Received 14 July 2004; accepted 13 September 2004)

\begin{abstract}
Sintering CdSe powder under argon flow at temperatures in the range $800-900{ }^{\circ} \mathrm{C}$ produces the formation of needles on the sample surface. Bundles of parallel needles of a diameter of about 50 $\mathrm{nm}$ give rise to a domain-like appearance in the sample. In addition, rods and needles with a wide range of dimensions up to several microns appear distributed in the surface. The influence of ball milling of the starting powder on the formation of the needles is investigated. Cathodoluminescence in the scanning electron microscope has been used to characterize the sintered samples. () 2004 American Institute of Physics. [DOI: 10.1063/1.1830083]
\end{abstract}

Fabrication and characterization of low-dimensional elongated semiconductor structures such as nanowires, nanotubes, or nanorods is a subject of increasing interest due to their potential use in future nanoelectronics systems or other technological applications. Fabrication and properties of such nanostructures of different semiconductors as, for instance, $\mathrm{ZnO},{ }^{1-5} \mathrm{Si}^{6}{ }^{6} \mathrm{TiO}_{2},{ }^{7} \mathrm{SnO}_{2},{ }^{8,9} \mathrm{Ga}_{2} \mathrm{O}_{3},{ }^{10,11}$ have been reported in the past years. Thermal evaporation of the semiconductor powder and deposition on a substrate under a gas flow is the most widely reported method to grow elongated structures. In the recent years, nanocrystalline CdSe has been obtained by several methods, such as ion implantation, ${ }^{12}$ chemical deposition, ${ }^{13}$ sol-gel methods, ${ }^{14}$ molecular-beam epitaxy, ${ }^{15}$ metalorganic chemical vapor deposition, ${ }^{16}$ or mechanical ball milling, ${ }^{17}$ but there are only few reports on the synthesis of elongated or quasi-one-dimensional CdSe nanostructures. Ma et al. ${ }^{18}$ recently reported a single-crystal nanoribbon structure of wurtzite CdSe. In this work, rod- and needle-shaped micro- and nanostructures were grown during sintering treatments of CdSe powder. The morphology and size of the structures have been investigated by scanning electron microscopy (SEM), while additional characterization was performed by cathodoluminescence (CL) in the SEM and by $x$-ray diffraction (XRD).

The starting material was commercial CdSe powder with a nominal purity of $99.999 \%$. The powder consisted of particles with sizes ranging from hundreds of nanometers to a few microns, as observed in the SEM. The powder was ball milled for $20 \mathrm{~h}$ in a centrifugal ball mill (Retsch S100) with $20 \mathrm{~mm}$ agatha balls. This treatment leads to aggregates of smaller particles, of about $100 \mathrm{~nm}$, and a more homogeneous size distribution. ${ }^{17}$ Samples were prepared by compacting the powders under a compressive load of 1 ton to form disks of about $7 \mathrm{~mm}$ in diameter and $2 \mathrm{~mm}$ thickness. The disks were then sintered under argon flow at temperatures of 600, 800, or $900{ }^{\circ} \mathrm{C}$. XRD measurements were performed in a Philips diffractometer working at $45 \mathrm{kV}$ and $40 \mathrm{~mA}$, using $\mathrm{Cu} \mathrm{K} \mathrm{K}_{\alpha}$ radiation. Secondary electron (SE) and CL observations were performed in a Leica 440 SEM or a Hitachi S2500 SEM. The CL measurements were carried out at liquid nitrogen temperature with a beam energy of $20 \mathrm{keV}$. CL images in the

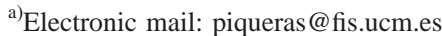

visible range were recorded with a Hamamatsu R928 photomultiplier and the CL spectra were obtained with a Hamamatsu PMA-11 CCD camera.

Treatment at $600{ }^{\circ} \mathrm{C}$ has not been found to produce changes in the sample appearance as observed in the SEM. Sintering at 800 or $900{ }^{\circ} \mathrm{C}$ during $5 \mathrm{~h}$ modify the sample surface, leading to the growth of different elongated structures. These changes are more marked at the higher temperature.

Sintering the milled powder at $900{ }^{\circ} \mathrm{C}$ leads to formation of protruding elongated structures distributed over the sample surface. They form a light interconnected network of long needles and rods that can be readily detached from the rest of the sample. The drastic change of the sample surface can be observed with naked eye. SEM observations show that in addition to the long protruding structures, the morphology of the surface background, which we describe first, is strongly modified by the sintering treatment. Figure 1 shows the SE image of the sample background. Bundles, with a size of several microns, formed by parallel oriented needles with transversal dimensions of about $50-100 \mathrm{~nm}$ are observed. The bundles have different orientations, which gives a domain-like appearance to the sample surface. This suggests an association to grains on which the growth of needles, with orientations related to the grain orientations,

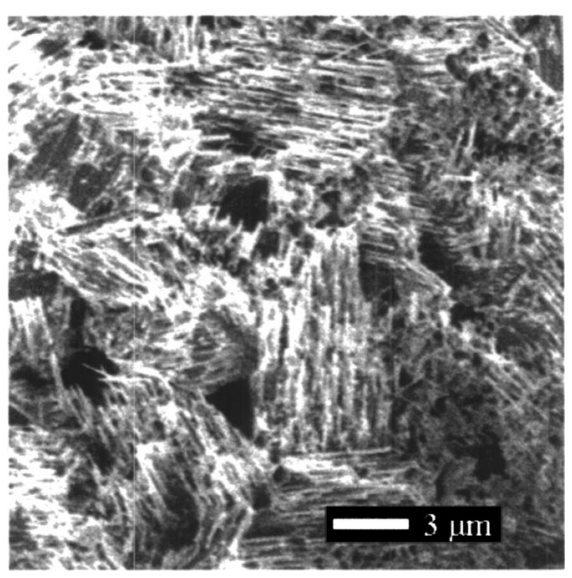

FIG. 1. SE image of the background of sample obtained from milled powder and sintered at $900{ }^{\circ} \mathrm{C}$. 


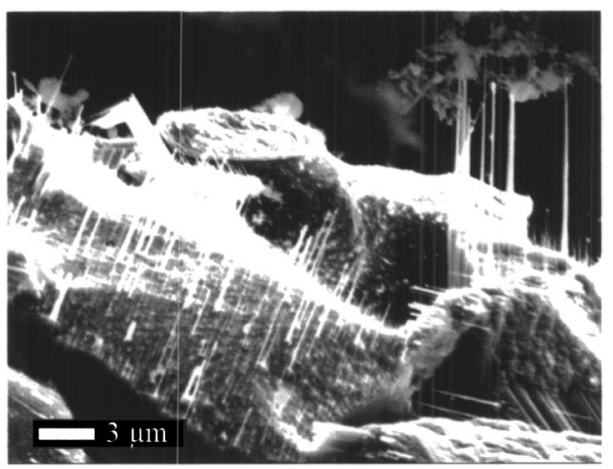

FIG. 2. SE image of the background of sample grown from unmilled powder and sintered at $900{ }^{\circ} \mathrm{C}$.

takes place. This possibility is supported by the observation of the sample sintered under the same conditions of temperature and flow, but prepared with unmilled powder. In this case, most of the grains have larger sizes and the needles seem to be in a preliminary stage of formation. Figure 2 shows some of these grains on which parallel needles, whose growth axis depends on the grain, are observed. A similar structure of parallel needles, but in a less compacted surface, is observed in the sample sintered at $800{ }^{\circ} \mathrm{C}$ (Fig. 3).

Regarding the long protruding structures, the needles or rods can reach a length of about $100 \mu \mathrm{m}$ as Fig. 4, of the sample treated at $800{ }^{\circ} \mathrm{C}$, shows. Some of the needles appear to develop on the top of well-faceted rods as those shown in Fig. 5(a), while in other cases a tree-like growth of large needles is observed [Fig. 5(b)]. No significant differences are observed in the protruding structures in samples prepared from milled and from unmilled powder. XRD shows that the structures are highly oriented, with peaks corresponding to hexagonal wurtzite with an intense (0001) peak. Since the preferred growth direction in wurtzite structure is the $c$-axis, this would be the axis of the needles. Milled powder presented before the sintering treatment a mixture of hexagonal and cubic phases. ${ }^{17}$

CL spectra of as-received and of milled powder have been previously described. ${ }^{17}$ Milling causes the appearance of an emission band at $2.5 \mathrm{eV}$ associated to the presence of nanocrystals with dimensions of some nanometers. Figure 6 shows the CL spectra recorded in the surface background of the samples sintered at 800 and $900{ }^{\circ} \mathrm{C}$, respectively. The spectrum after the $800{ }^{\circ} \mathrm{C}$ treatment consists of a band peaked at about $1.79 \mathrm{eV}$, which corresponds to near-band-

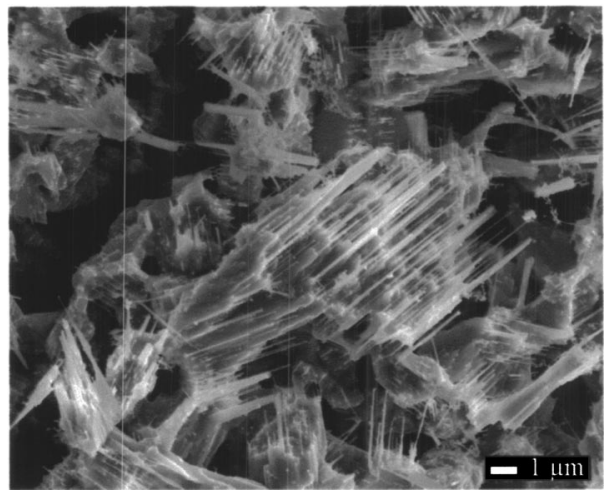

FIG. 3. SE image of the background of sample obtained from milled powder and annealed at $800{ }^{\circ} \mathrm{C}$.

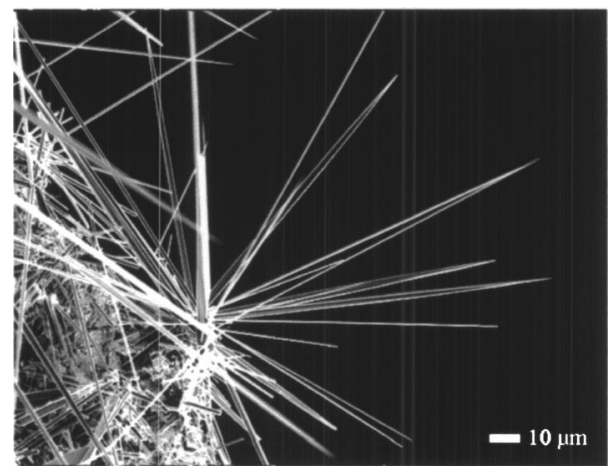

FIG. 4. SE image of rods grown on sample treated at $800{ }^{\circ} \mathrm{C}$.

edge transitions, a shoulder at $1.77 \mathrm{eV}$ possibly related to dislocations, ${ }^{19}$ and a broad band at $1.69 \mathrm{eV}$, which includes several donor-acceptor transitions. In the samples sintered at $900{ }^{\circ} \mathrm{C}$, only the high-energy band, peaked at about $1.81 \mathrm{eV}$, is observed, which would be due to annealing of dislocations and other defects during the high-temperature treatment. CL spectra of areas formed mainly by the protruding structures show the near-band-edge emission band as well as emission bands in the range 1.65-1.75 eV depending on the sample and on the area probed. CL images and local spectra reveal that the needles often show regions with enhanced CL emission in the range $1.6-1.7 \mathrm{eV}$. The high CL intensity regions are usually sets of parallel rings transverse to the needle axis. Figure 7 shows the CL image of a tree-like needle arrangement showing the luminescent rings. It is suggested that the origin of the high CL intensity of the rings is the accumulation of radiative centers, related to point defects or stacking faults, during the growth process.

Although most of the elongated structures have a needle or rod shape, hexagonal rods with thick walls and a central hollow have been occasionally observed. This would correspond to an early stage of rod or needle formation and indicates the possibility of fabricating tubular structures by the method described here. Figure 8 shows the SE and CL images of one of the tubes. It is observed that the internal part of the tube presents enhanced CL emission.

As mentioned earlier, thermal evaporation of powders under a gas flow followed by a deposition on a substrate has been often reported as a method to obtain nanowires, nanorods, or nanotubes of different semiconductors. The growth takes place either by catalyst-assisted technique ${ }^{20}$ or by a vapor-solid process. ${ }^{1}$ In the present work, the source, a disk-
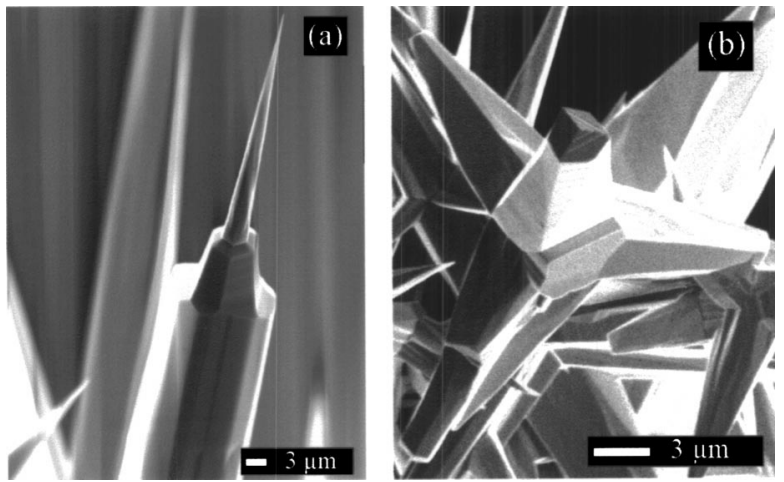

FIG. 5. Scanning electron micrographs of (a) faceted rod with needle and (b) tree-like needles. 


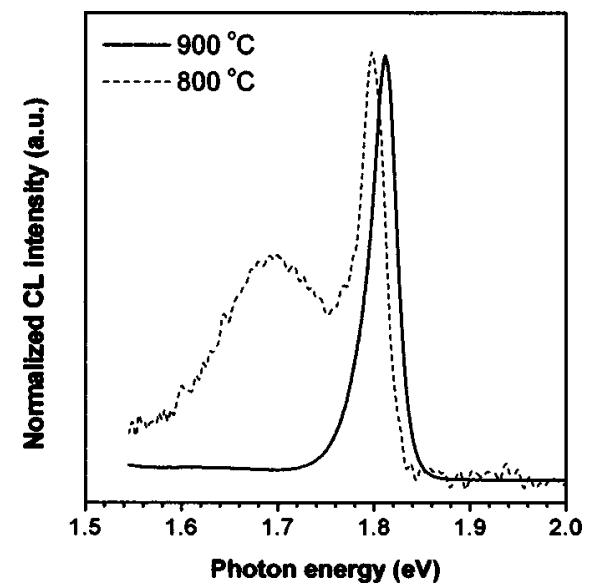

FIG. 6. Normalized CL spectra recorded at liquid nitrogen temperature on sample treated at $900{ }^{\circ} \mathrm{C}$ (continuous line) and $800{ }^{\circ} \mathrm{C}$ (dashed line).

shaped sample, is also the substrate for the growth of the structures. Since neither a catalytic process nor a foreign substrate is involved, it appears that the formation of the structures takes place by a vapor-solid process.

In summary, sintering of CdSe compacted powder under argon flow in the temperature range $800-900{ }^{\circ} \mathrm{C}$ leads to the formation of micro- and nanoneedles on the sample surface. The surface background appears formed by oriented bundles of nanoneedles which gives a domain-like appearance to the sample. Protruding structures in the form of needles, rods, and occasionally tubes are also formed in the sample. Mechanical ball milling of the starting powder has been found to favor the formation and the homogeneity of the needle

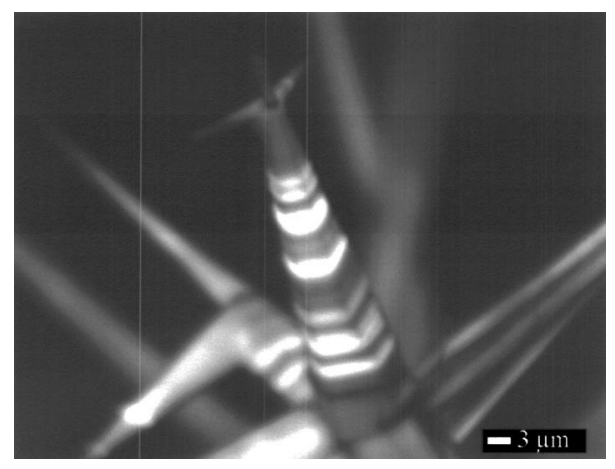

FIG. 7. CL image of tree-like needles showing luminescence rings.
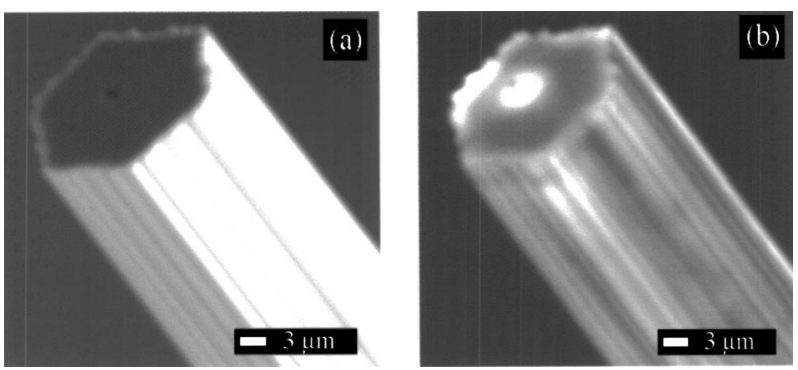

FIG. 8. SE (a) and CL (b) images of a CdSe tube.

structure. CL measurements show the presence of different low-energy emission bands in the sintered samples as well as regions of enhanced intensity in the needles.

This work has been supported by MEC (Project MAT2003-00455).

${ }^{1}$ Z. W. Pan, Z. R. Dai, and Z. L. Wang, Science 291, 1947 (2001).

${ }^{2}$ H. T. Ng, B. Chen, J. Li, J. Han, M. Meyyappan, J. Wu, S. X. Li, and E. E. Haller, Appl. Phys. Lett. 82, 2023 (2003).

${ }^{3}$ J.-S. Lee, K. Park, M.-I. Kang, I.-W. Park, S.-W. Kim, W. K. Cho, H. S. Han, and S. Kim, J. Cryst. Growth 254, 423 (2003).

${ }^{4}$ J. Q. Hu and Y. Bando, Appl. Phys. Lett. 82, 1401 (2003).

${ }^{5}$ Y. J. Xing, Z. H. Xi, Z. Q. Xue, X. D. Zhang, J. H. Song, R. M. Wang, J. Xu, Y. Song, S. L. Zhang, and D. P. Yu, Appl. Phys. Lett. 83, 1689 (2003).

${ }^{6}$ Y. H. Tang, Y. F. Zhang, N. wang, C. S. Lee, X. D. Han, I. Bello, and S.

T. Lee, J. Appl. Phys. 85, 7981 (1999).

${ }^{7}$ G. H. Du, Q. Chen, R. C. Che, Z. Y. Yuan, and L. M. Peng, Appl. Phys. Lett. 79, 3702 (2001).

${ }^{8}$ Z. R. Dai, Z. W. Pan, and Z. L. Wang, Solid State Commun. 118, 351 (2001).

${ }^{9}$ Z. R. Dai, J. L. Gole, J. D. Stout, and Z. L. Wang, J. Phys. Chem. B 106, 1274 (2002).

${ }^{10}$ S. Sharma and M. K. Sunkara, J. Am. Chem. Soc. 124, 12288 (2002).

${ }^{11}$ Y. P. Song, H. Z. Zhang, C. Lin, Y. W. Zhu, G. H. Li, F. H. Yang, and D. P. Yu, Phys. Rev. B 69, 075304 (2004).

${ }^{12}$ W. Hipp, H. Karl, I. Großhans, and B. Strikzker, Mater. Sci. Eng., B 101, 318 (2003).

${ }^{13}$ X. W. Zhou, R. F. Lin, and X. R. Xiao, Appl. Surf. Sci. 119, 203 (1997).

${ }^{14}$ R. Reisfeld, J. Alloys Compd. 341, 56 (2002).

${ }^{15}$ I. Yamakawa, M. Ichida, S. V. Sorokin, A. A. Toropov, A. N. Titkov, S. V. Ivanov, and A. Nakamura, J. Lumin. 87-89, 384 (2000).

${ }^{16}$ J. Rodríguez-Viejo, K. F. Jensen, A. Mattoussi, J. Michel, B. O. Dabbousi, and M. G. Bawendi, Appl. Phys. Lett. 70, 2132 (1997).

${ }^{17}$ A. Urbieta, P. Fernández, and J. Piqueras, J. Appl. Phys. 96, 2210 (2004).

${ }^{18}$ C. Ma, Y. Ding, D. Moore, X. Wang, and Z. L. Wang, J. Am. Chem. Soc. 126, 708 (2004).

${ }^{19}$ N. I. Tarbaev, Phys. Solid State 40, 1672 (1998).

${ }^{20}$ A. M. Morales and C. M. Lieber, Science 279, 208 (1998). 